Pesq. Vet. Bras. 38(5):957-966, maio 2018

\title{
Soropositividade e fatores de risco para leptospirose, toxoplasmose e neosporose na população canina do Estado da Paraíba ${ }^{1}$
}

\author{
Annielle R.F. Fernandes², Diego F. Costa ${ }^{2}$, Muller R. Andrade ${ }^{3}$, Camila S. Bezerra², \\ Rinaldo A. Mota ${ }^{3}$, Clebert J. Alves ${ }^{2}$, Hélio Langoni ${ }^{4}$ e Sérgio S. Azevedo ${ }^{2 *}$
}

\begin{abstract}
Fernandes A.R.F., Costa D.F., Andrade M.R., Bezerra C.S., Mota R.A., Alves C.J., Langoni H. \& Azevedo S.S. 2018. [Seropositivity and risk factors for leptospirosis, toxoplasmosis and neosporosis in the canine population of Paraiba state, northeastern Brazil.] Soropositividade e fatores de risco para leptospirose, toxoplasmose e neosporose na população canina do Estado da Paraíba. Pesquisa Veterinária Brasileira 38(5):957-966. Laboratório de Doenças Transmissíveis, Unidade Acadêmica de Medicina Veterinária, Universidade Federal de Campina Grande, Av. Universitária s/n, Santa Cecília, Patos, PB 58700-970, Brazil. E-mail: sergio@vps.fmvz.usp.br

The aim of this study was to determine the frequency of seropositive animals for Leptospira spp., Toxoplasma gondii and Neospora caninum in dogs from Paraiba state, northeastern Brazil, and to identify risk factors. A total of 1,043 sera were sampled from dogs from five urban centers considered as regional poles: João Pessoa, Campina Grande, Patos, Sousa and Cajazeiras. For the serological diagnosis of Leptospira spp. infection the microscopic agglutination test (MAT) was used, and for detecting anti-T. gondii and N. caninum antibodies the indirect fluorescent antiboy test (IFAT) was carried out. Ninety-seven dogs showed anti-Leptospira spp. agglutinins, resulting in a frequency of 9.3\% (95\% CI=7.5; $11.1 \%)$. The most frequente serovars were Icterohaemorragiae (47.4\%), Copenhageni (16.5\%), Bratislava (11.3\%), Canicola (10.3\%) and Pomona (6.2\%). The seropositivities for T. gondii and $N$. caninum were $22.1 \%(231 / 1043 ; 95 \% \mathrm{CI}=19.6 ; 24.7 \%)$ and $7.7 \%(80 / 1043$; $95 \% \mathrm{CI}=6.1 ; 9.3 \%$ ) respectively. Age $>48$ months (OR=2.92), mixed breed (OR=1.94) and access to street $(\mathrm{OR}=1.57)$ were identified as risk factors for Leptospira spp. infection. For toxoplasmosis, the categories age $>48$ months $(\mathrm{OR}=1.74)$, homemade food $(\mathrm{OR}=2.24)$, comercial and homemade food $(\mathrm{OR}=2.34)$ and contact with cats $(\mathrm{OR}=1.57)$ were considered risk factors, while access to street $(\mathrm{OR}=2.62)$ was risk fator for $N$. caninum. We conclude that dogs from five urban centers in Paraiba state are exposed to Leptospira spp., T. gondii and $N$. caninum infections, evidenced by antibody detection, as well as it is suggested a better feed management, control of outside home environment access and proper disposal of cat feces.

INDEX TERMS: Seropositivity, leptospirosis, toxoplasmosis, neosporosis, dogs, Leptospira spp., Toxoplasma gondii, Neospora caninum, risk factors, bacterioses, parasitoses.
\end{abstract}

\footnotetext{
${ }^{1}$ Recebido em 8 de abril de 2017.

Aceito para publicação em 21 de abril de 2017.

${ }^{2}$ Laboratório de Doenças Transmissíveis, Unidade Acadêmica de Medicina Veterinária, Universidade Federal de Campina Grande (UFCG), Campus de Patos, Av. Universitária s/n, Santa Cecília, Patos, PB 58700-970, Brasil. *Autor para correspondência: sergio@vps.fmvz.usp.br

${ }^{3}$ Laboratório de Doenças Infectocontagiosas dos Animais Domésticos, Departamento de Medicina Veterinária, Universidade Federal Rural de Pernambuco (UFRPE), Rua Dom Manoel de Medeiros s/n, Dois Irmãos, Recife, PE 52171-900, Brasil.

${ }^{4}$ Departamento de Higiene Veterinária e Saúde Pública, Faculdade de Medicina Veterinária e Zootecnia (FMVZ), Universidade Estadual Paulista (Unesp), Campus de Botucatu, Distrito de Rubião Júnior, Botucatu, SP 18618-970, Brasil.
}

RESUMO.- Objetivou-se com este trabalho determinar a frequência de animais soropositivos para Leptospira spp., Toxoplasma gondii e Neospora caninum em cães do Estado da Paraíba, Nordeste do Brasil, bem como identificar fatores de risco. Foram amostrados 1.043 soros de cães procedentes de cinco centros urbanos considerados polos regionais: João Pessoa, Campina Grande, Patos, Sousa e Cajazeiras. Para o diagnóstico sorológico da infecção por Leptospira spp. foi utilizada a soroaglutinação microscópica (SAM) enquanto que para detecção de anticorpos anti-T. gondii e $N$. caninum empregou-se a reação de imunofluorescência 
indireta (RIFI). Noventa e sete cães apresentaram aglutininas anti-Leptospira spp., resultando em frequência de 9,3\% (IC 95\% = 7,5-11,1\%). Os sorovares de maior frequência foram Icterohaemorragiae $(47,4 \%)$, Copenhageni $(16,5 \%)$, Bratislava (11,3\%), Canicola $(10,3 \%)$ e Pomona $(6,2 \%)$. Observou-se soropositividade de 22,1\% (231/1.043; IC 95\% $=19,6-24,7 \%)$ e $7,7 \%(80 / 1.043$; IC $95 \%=6,1-9,3 \%)$ para T. gondii e $N$. caninum, respectivamente. Idade $>48$ meses $(\mathrm{OR}=2,92)$, raça não definida $(\mathrm{OR}=1,94)$ e criação com acesso à rua $(\mathrm{OR}=1,57)$ foram apontados como fatores de risco para infecção por Leptospira spp. Para toxoplasmose, as categorias idade $>48$ meses $(\mathrm{OR}=1,74)$, alimentação com comida caseira $(\mathrm{OR}=2,24)$, alimentação com ração e comida caseira (OR=2,34) e contato com gatos $(\mathrm{OR}=1,57)$ foram consideradas fatores de risco, enquanto que a criação com acesso à rua $(\mathrm{OR}=2,62)$ foi fator de risco para $N$. caninum. Conclui-se que cães de cinco centros urbanos do Estado da Paraíba estão expostos às infecções por Leptospira spp., T. gondii e N. caninum, evidenciadas pela detecção de anticorpos, bem como sugerese melhor manejo alimentar, controle no acesso a ambientes externos e destino adequado das fezes de gatos.

TERMOS DE INDEXAÇÃO: Soropositividade, leptospirose, toxoplasmose, neosporose, caninos, Leptospira spp., Toxoplasma gondii, Neospora caninum, fatores de risco, bacterioses, parasitoses.

\section{INTRODUÇÃO}

A estreita relação entre cão e ser humano ao longo dos anos garantiu que infecções consideradas importantes em regiões tropicais como a leptospirose, toxoplasmose e neosporose se tornassem objeto de atenção e investigação, uma vez que os cães podem atuar como fontes de infecção para leptospirose e neosporose, bem como são considerados sentinelas para toxoplasmose (Coiro et al. 2011).

A leptospirose é uma doença infectocontagiosa causada por bactérias do gênero Leptospira. Atualmente são reconhecidas 20 espécies por homologia de DNA e, em cada espécie, são identificados vários sorovares. Essas diferentes espécies são classificadas em três grupos: patogênicas, intermediárias/oportunistas e não patogênicas (Paes 2016). 0 homem, os animais domésticos e várias espécies de animais selvagens podem ser infectados por leptospiras, sendo referidas duas categorias da doença com implicações clínicas diferentes: quando o animal é infectado com um sorovar hospedeiro-adaptado, tornando-se reservatório; e quando animais susceptíveis são expostos a sorovares não adaptados, causando a doença acidental, forma comum também nos humanos. Nas duas situações, os animais infectados eliminam leptospiras pela urina por período de semanas a meses, contaminando o ambiente (Ellis 2015).

0 principal reservatório de Leptospira spp. no meio urbano é reconhecidamente o rato, particularmente o Rattus norvegicus, que alberga a bactéria de forma permanente, principalmente os membros do sorogrupo Icterohaemorrhagiae, sendo capaz de eliminá-la de forma intermitente e por longos períodos pela urina (Ellis 2015). No entanto, entre os animais domésticos, o cão tem grande importância na transmissão ao homem em função do contato estreito, podendo ser importante fonte de infecção por excretar leptospiras pela urina por longos períodos; além disso, o contato indireto com água ou solo contaminado com leptospiras também são vias de transmissão comuns para seres humanos (Fernandes et al. 2013).

Toxoplasmose e neosporose são doenças parasitárias causadas por protozoários antigenicamente relacionados e de distribuição mundial, Toxoplasma gondii e Neospora caninum, responsáveis por distúrbios neurológicos, gastrintestinais, respiratórios e musculares em cães. Os felinos são considerados hospedeiros definitivos de T. gondii, e N. caninum tem como hospedeiros definitivos o cão e canídeos silvestres (McAllister et al. 1998, Gondim et al. 2004, King et al. 2010, Dubey et al. 2011). Para ambos os agentes várias espécies podem atuar como hospedeiros intermediários, contudo, na infecção por $N$. caninum os bovinos merecem destaque pelos danos reprodutivos e produtivos que o agente ocasiona (Reichel et al. 2013).

A toxoplasmose é um sério problema de saúde pública, uma vez que a doença clínica ocorre em grupos de risco, representados principalmente por mulheres grávidas e indivíduos imunocomprometidos. Os seres humanos adquirem a infecção pela ingestão de alimentos e água contaminados com oocistos esporulados ou ainda pelo consumo de carne crua ou mal cozida de animais de produção, especialmente suínos, caprinos e ovinos contendo cistos teciduais (Dubey et al. 2012). Os cães são considerados um risco potencial para a transmissão do agente, pois podem mecanicamente transmitir oocistos ao homem (Dubey et al. 2007). A infecção da população canina é uma indicação do ambiente doméstico contaminado pelo T. gondii, com consequente risco de contaminação para a população humana, ligado ao fato de que tanto o homem quanto os cães estão expostos a um veículo de contaminação comum, representado pelo ambiente e hábitos alimentares. Dessa forma, a espécie canina pode ser considerada animal sentinela para a infecção (Coiro et al. 2011). Não há relatos de casos de neosporose em humanos, embora já tenham sido detectados anticorpos para $N$. caninum em pacientes com HIV (Lobato et al. 2006).

No Estado da Paraíba não há estudos epidemiológicos para leptospirose, toxoplasmose e neosporose em cães conduzidos com base em amostragem planejada e contemplando vários centros urbanos. Dessa maneira, tendo em vista a relevância dessas doenças em saúde pública e o papel dos cães na epidemiologia, o objetivo desse trabalho foi determinar indicadores epidemiológicos (soropositividade e fatores de risco) na população canina de cinco centros urbanos da Paraíba.

\section{MATERIAL E MÉTODOS}

Amostragem. Foram utilizados cães com idade acima de três meses provenientes de visitas às residências de seus proprietários, atendimentos em clínicas e laboratórios de análises clínicas veterinárias. Os animais foram procedentes dos municípios de João Pessoa, Campina Grande, Patos, Sousa e Cajazeiras (Fig.1), considerados polos regionais no Estado da Paraíba e localizados ao longo de uma das principais rodovias, a BR-230 (Rodovia Transamazônica). A amostra foi calculada a partir da população total de cães dos cinco municípios, estimada em 141.863 animais (6.843 animais em Sousa, 10.553 em Patos, 78.073 em João Pessoa, 6.103 em Cajazeiras e 40.291 em Campina Grande). Esta estimativa foi baseada nos dados de população humana do Instituto Brasileiro de Geografia e Estatística (IBGE), para o ano de 2013. Para o cálculo da proporção cão/homem no meio urbano, foi utilizada a relação de 1:10 (WHO 1990, Reichmann et al. 1999). 0 tamanho da amostra foi 

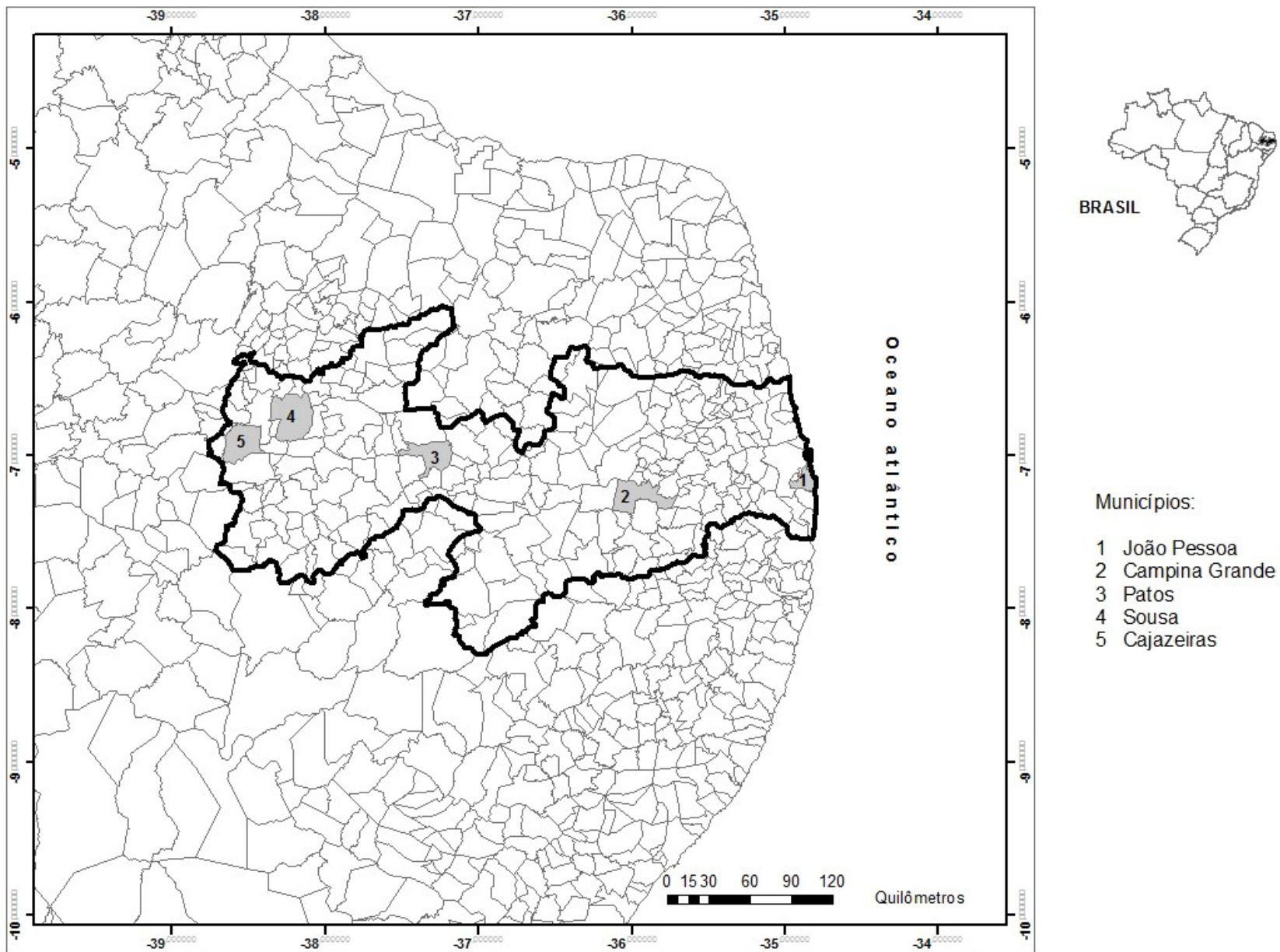

Municipios:

1 João Pessoa

2 Campina Grande

3 Patos

4 Sousa

5 Cajazeiras

Fig.1. Distribuição geográfica dos municípios utilizados. A localização da Paraíba dentro do Brasil é demonstrada no detalhe.

calculado para cada município com uma estimativa de positividade de $50 \%$ (valor adotado para maximização da amostra), nível de confiança de $95 \%$ e erro de $10 \%$ (Thrusfield 2007), o que gerou um tamanho amostral de no mínimo 96 animais por município. No entanto, foram utilizados 1.043 animais distribuídos da seguinte maneira: 125 animais em Sousa, 206 em Patos, 338 em João Pessoa, 125 em Cajazeiras e 249 em Campina Grande.

Não foram estabelecidos critérios probabilísticos para a seleção dos animais, de maneira que a inclusão do animal na pesquisa ficou condicionada ao contato prévio e consentimento do proprietário. As amostras de sangue foram colhidas no período de janeiro de 2013 a dezembro de 2014, por punção das veias jugular externa ou cefálica utilizando-se seringas descartáveis de $5 \mathrm{~mL}$, com posterior obtenção do soro e estocagem a $-20^{\circ} \mathrm{C}$ até a realização da sorologia.

Diagnóstico sorológico. Para o diagnóstico sorológico da infecção por Leptospira spp. foi utilizada a técnica de soroaglutinação microscópica (OIE 2014). Utilizou-se como antígenos uma coleção de cepas de Leptospira interrogans sorotipos Australis, Copenhageni, Bataviae, Bratislava, Canicola, Grippotyphosa, Hardjoprajitno, Pomona, Icterohaemorrhagiae, Hebdomadis, Djasiman, Wolffi; Leptospira borgpeterseni sorotipos Autumnalis, Castellonis, Hardjobovis, Tarassovi, Sejroe; Leptospira santarosai sorotipo Guaricura; Leptospira kirschneri sorotipo Cynopteri; e Leptospira noguchii sorotipo Panama, todas cedidas pelo Laboratório de Bacteriologia Veterinária da Universidade Federal Fluminense (UFF) e oriundas do Instituto Pasteur, França. Os soros foram triados na diluição de 1:100, e aqueles que apresentaram $50 \%$ ou mais de aglutinação foram titulados pelo exame de uma série de diluições geométricas de razão dois. 0 título do soro foi a recíproca da maior diluição que apresentou resultado positivo. Animais com título $\geq 100$ foram considerados positivos. Os antígenos foram examinados ao microscópio de campo escuro, previamente aos testes, a fim de verificar a mobilidade e a presença de auto-aglutinação ou de contaminantes.

A detecção de anticorpos anti-Toxoplasma gondii e anti-N. caninum foi realizada através da reação de imunofluorescência indireta (RIFI), segundo metodologia descrita por Camargo (1964) e Dubey et al. (1988), respectivamente. Lâminas para imunofluorescência foram sensibilizadas com taquizoítos de $T$. gondii da cepa $\mathrm{RH}$ ou de $N$. caninum da cepa NC-1, purificadas a partir do cultivo celular. Os soros para ambos os agentes foram diluídos em solução salina tamponada (pH 7,2), adotando-se como ponto de corte as diluições 1:64 para T. gondii e 1:50 para Neospora caninum. Para a visualização da reação foi utilizado o anticorpo comercial anti-IgG canino (Sigma, USA) conjugado com isotiocianato de fluoresceína. As amostras que marcavam mais de $50 \%$ dos taquizoítos do poço com fluorescência periférica total foram consideradas positivas e submetidas a diluições sucessivas, adotando-se como título final o correspondente a última diluição com reação positiva.

Questionário epidemiológico. Na ocasião das colheitas de sangue os proprietários dos cães responderam a um questionário epidemiológico que foi elaborado de modo a fornecer variáveis com o intuito de verificar a ausência ou presença de algumas práticas e 
condições que pudessem atuar como possíveis fatores de risco para as doenças. As variáveis analisadas e as respectivas categorias foram: nível de escolaridade do proprietário (analfabeto, $1^{\circ}$ grau, $2^{\circ}$ grau, 3o grau), sexo (macho, fêmea), idade ( $\leq 12$ meses, 13-48 meses, $>48$ meses), raça (sem raça definida, com raça definida), tipo de criação (domiciliar, com acesso à rua), alimentação (ração comercial, comida caseira, ração e comida caseira), contato com cães (não, sim), contato com bovinos (não, sim), contato com equinos (não, sim), contato com gatos (não, sim), contato com caprinos/ovinos (não, sim), contato com suínos (não, sim), contato com animais silvestres (não, sim), ambiente (terra, cimento, terra e cimento), limpeza do ambiente (não, sim), vacinação (não, sim), passeio (não, sim), viagem (não, sim), presença de ratos (não, sim) e acesso a açudes (não, sim).

Análise de fatores de risco. A análise dos fatores de risco foi efetuada com os dados coletados com os questionários epidemiológicos e foi efetuada em duas etapas: análise univariável e análise multivariável. Na análise univariável, foram formados dois grupos de animais - soropositivos e soronegativos - que foram comparados frente às variáveis analisadas. Aquelas variáveis que apresentaram valor de $P \leq 0,2$ pelo teste de qui-quadrado ou teste exato de Fisher (Zar 1999) foram selecionadas para a análise multivariável, utilizando-se regressão logística múltipla (Hosmer \& Lemeshow 2000). 0 ajuste do modelo final foi verificado com o teste de Hosmer e Lemeshow, pelo qual um valor de $P>0,05$ indica ajuste adequado, e a colinearidade entre variáveis independentes foi avaliada por análise de correlação; para aquelas variáveis com forte colinearidade (coeficiente de correlação >0,9), uma das duas variáveis foi excluída da análise múltipla de acordo com a plausibilidade biológica (Dohoo et al. 1997). A influência de variáveis de confusão foi verificada pelo monitoramento de mudanças nos parâmetros no modelo final após a adição de novas variáveis. Mudanças substanciais (acima de 20\%) nos coeficientes de regressão foram indicativas de confundimento. 0 nível de significância adotado na análise múltipla foi de $5 \%$, e todas as análises foram realizadas com o programa SPSS 20.0 for Windows.

\section{RESULTADOS}

A frequência de animais soropositivos para Leptospira spp. foi de 9,3\% (97/1043) cujos títulos variaram de 100 a 400, predominando as reações para os sorovares Icterohaemorrhagiae com 47,4\% (46/97), seguido pelo sorovar Copenhageni com $16,5 \%$ (16/97), Bratislava 11,3\% (11/97), Canicola 10,3\% (10/97), Pomona 6,2\% (6/97), Grippothyphosa 3,1\% (3/97), Australis e Castellonis com 2,1\% (2/97) para cada sorovar, além do sorovar Bataviae com 1\% (1/97). Observou-se presença de anticorpos contra T. gondii em 22,1\% (231/1043) dos animais, sendo que $65(28,1 \%)$ deles apresentaram título 16, 24 (10,4\%) com título 32, 82 (35,5\%) título 64, 24 (10,4\%) título 128, 35 $(15,2 \%)$ título 256 e um $(0,4 \%)$ animal reagiu até a titulação 4.096. Quanto à neosporose, 7,7\% (80/1043) dos cães foram soropositivos com 55 (68,8\%) animais apresentando título $50,17(21,2 \%)$ título 100 e oito (10\%) título 200. No Quadro 1 é apresentada a distribuição dos animais soropositivos de acordo com o município de origem.

$\mathrm{Na}$ análise de fatores de risco (Quadro 2) para leptospirose, foram selecionadas, na análise univariável $(P \leq 0,2)$, as seguintes variáveis: idade $(P=0,005)$, raça $(P=0,012)$, tipo de criação $(P=0,006)$, contato com cães $(P=0,093)$. Na regressão logística, as categorias idade $>48$ meses $(\mathrm{OR}=2,92)$, raça não definida $(\mathrm{OR}=1,94)$ e criação com acesso à rua $(\mathrm{OR}=1,57)$ foram apontadas como fatores de risco para infecção por Leptospira spp. (Quadro 3). Para toxoplasmose, foram selecionadas na análise univariável as variáveis (Quadro 2): nível de escolaridade do proprietário $(P=0,012)$, idade $(P=0,021)$, tipo de criação $(P=0,003)$, alimentação $(P<0,001)$, contato com bovinos $(P=0,011)$, contato com gatos $(P<0,001)$, contato com caprino/ovino $(P=0,007)$, limpeza do ambiente $(P=0,004)$, presença de ratos $(P<0,001)$ e acesso à açudes $(P<0,001)$. Após regressão logística (Quadro 3), idade $>48$ meses $(O R=1,74)$, alimentação com comida caseira $(\mathrm{OR}=2,24)$, alimentação com ração e comida caseira $(\mathrm{OR}=2,34)$ e contato com gatos $(\mathrm{OR}=1,57)$ foram considerados fatores de risco. Já para neosporose foram selecionadas na análise univariável: nível de escolaridade do proprietário $(P=0,194)$, tipo de criação $(P<0,001)$, alimentação $(P=0,078)$, contato com bovinos $(P=0,147)$, presença de ratos $(P=0,155)$ (Quadro 2). Realizada a regressão logística, apenas a categoria criação com acesso à rua $(\mathrm{OR}=2,62)$ foi apontada como fator de risco (Quadro 3). Os modelos finais de regressão logística apresentaram bom ajuste $(P>0,05$; teste de Hosmer e Lemeshow).

\section{DISCUSSÃO}

De acordo com Ellis (2015), a realização de inquéritos sorológicos exercem papel de relevância indiscutível no controle da leptospirose, pois permitem o conhecimento dos diferentes sorogrupos existentes em determinada região, de modo que vários trabalhos investigando a presença de anticorpos anti-Leptospira spp. foram conduzidos no Brasil. Resultados superiores aos do presente estudo foram obtidos por Magalhães et al. (2006) em Belo Horizonte/MG, Silva et al. (2009) em Botucatu/SP, Castro et al. (2011) em Uberlândia/MG e mais recentemente por Mascolli et al. (2016) em Ibiúna/SP com 13,1\% (448/3417), 17,9\% (179/1000), 28,4\% (76/268) e $32,8 \%(187 / 570)$, respectivamente. Frequências relativamente

Quadro 1. Soropositividade para leptospirose, toxoplasmose e neosporose em cães do Estado da Paraíba, de janeiro de 2013 a dezembro de 2014

\begin{tabular}{|c|c|c|c|c|c|c|c|c|c|c|c|}
\hline \multirow{2}{*}{ Cidade } & \multicolumn{2}{|c|}{ Número de cães } & \multicolumn{3}{|c|}{ Leptospirose } & \multicolumn{3}{|c|}{ Toxoplasmose } & \multicolumn{3}{|c|}{ Neosporose } \\
\hline & Total & Amostragem & Positivos & $\%$ & IC $95 \%$ & Positivos & $\%$ & IC $95 \%$ & Positivos & $\%$ & IC $95 \%$ \\
\hline Sousa & 6.843 & 125 & 19 & 15,2 & $8,4-21,5$ & 41 & 32,8 & $24,6-41,0$ & 39 & 31,2 & $23,1-39,3$ \\
\hline Patos & 10.553 & 206 & 16 & 7,7 & $4,1-11,4$ & 29 & 14,0 & $9,6-18,8$ & 12 & 5,8 & $2,6-9,0$ \\
\hline João Pessoa & 78.073 & 338 & 24 & 7,1 & $4,4-9,8$ & 38 & 11,2 & $7,9-14,6$ & 6 & 1,7 & $0,4-3,2$ \\
\hline Cajazeiras & 6.103 & 125 & 11 & 8,8 & $3,8-13,8$ & 75 & 60,0 & $51,4-68,6$ & 18 & 14,4 & $8,2-20,6$ \\
\hline Campina Grande & 40.291 & 249 & 27 & 10,8 & $7,0-14,7$ & 48 & 19,3 & $14,4-24,2$ & 5 & 2,0 & $0,9-4,6$ \\
\hline TOTAL & 141.863 & 1.043 & 97 & 9,3 & $7,5-11,1$ & 231 & 22,1 & $19,6-24,7$ & 80 & 7,7 & $6,1-9,3$ \\
\hline
\end{tabular}


Quadro 2. Análise univariável dos fatores de risco associados à soropositividade para toxoplasmose, neosporose e leptospirose em 1.043 cães de janeiro 2013 a dezembro 2014, no Estado da Paraíba

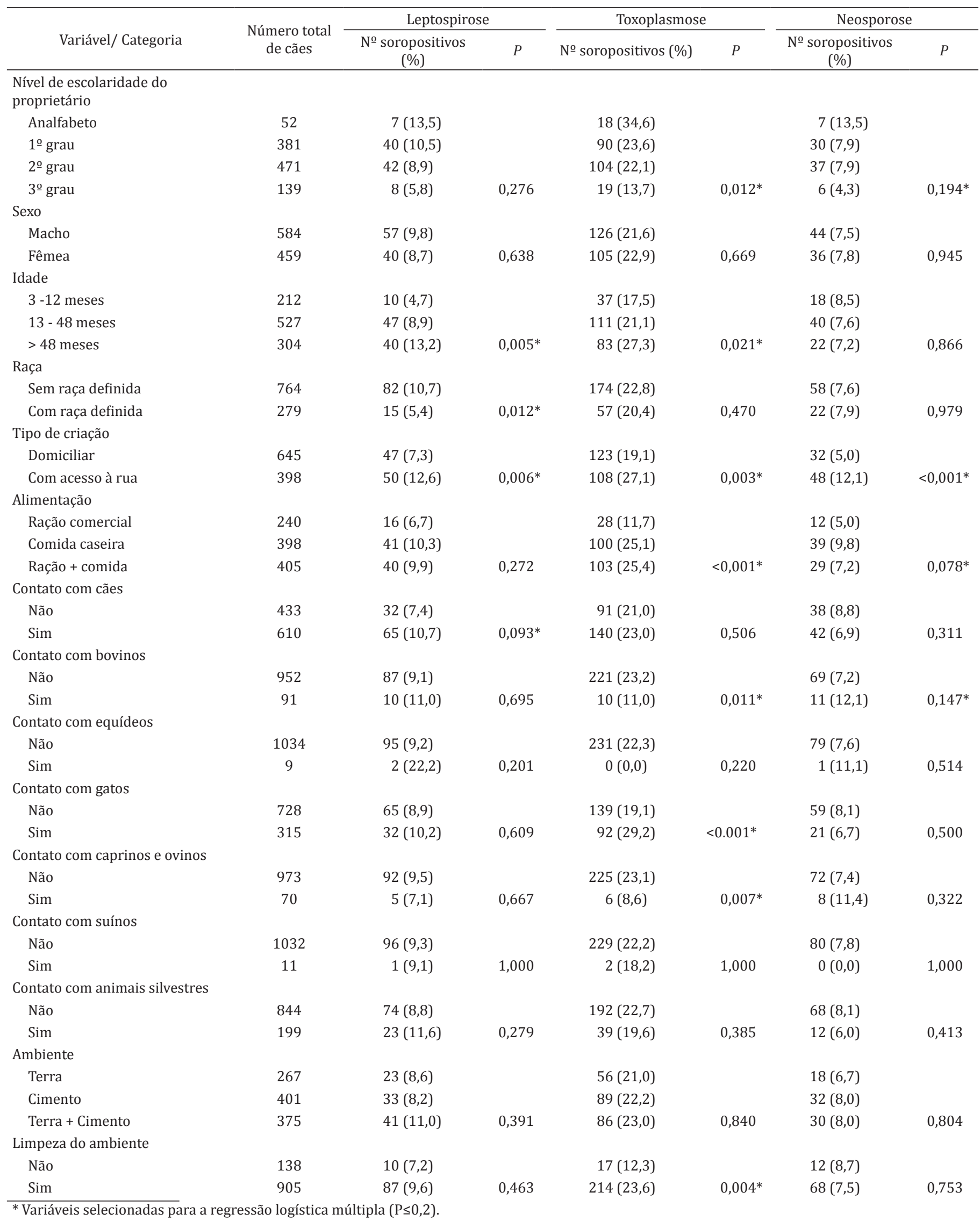


Quadro 2. Continua...

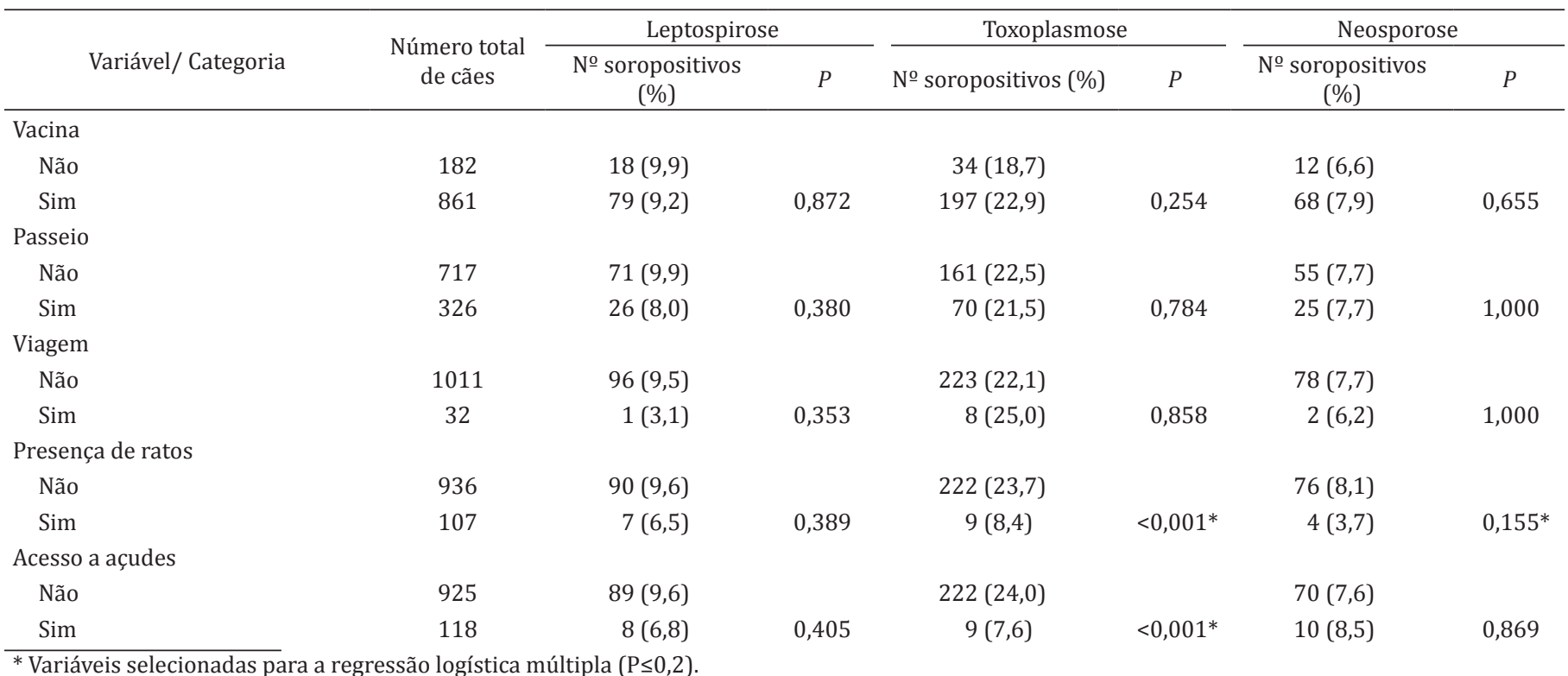

Quadro 3. Fatores de risco associados com a soropositividade para toxoplasmose, neosporose e leptospirose em 1.043 cães de janeiro de 2013 a dezembro de 2014, no Estado da Paraíba

\begin{tabular}{|c|c|c|c|c|c|c|}
\hline Fator de risco & $\begin{array}{c}\text { Coeficiente de } \\
\text { regressão }\end{array}$ & Erro Padrão & Wald & Odds ratio (OR) & IC 95\% & $P$ \\
\hline \multicolumn{7}{|l|}{ Leptospirose $^{\mathrm{a}}$} \\
\hline Idade > 48 meses & 1,072 & 0,368 & 8,490 & 2,92 & $1,42-6,01$ & 0,004 \\
\hline Raça não definida & 0,663 & 0,296 & 5,027 & 1,94 & $1,08-3,46$ & 0,025 \\
\hline Criação com acesso à rua & 0,457 & 0,219 & 4,349 & 1,57 & $1,02-2,42$ & 0,037 \\
\hline \multicolumn{7}{|l|}{ Toxoplasmose $\mathrm{e}^{\mathrm{b}}$} \\
\hline Idade $>48$ meses & 0,556 & 0,226 & 6,061 & 1,74 & $1,12-2,71$ & 0,014 \\
\hline Comida caseira & 0,808 & 0,238 & 11,553 & 2,24 & $1,40-3,57$ & 0,001 \\
\hline Ração + comida caseira & 0,852 & 0,234 & 13,289 & 2,34 & $1,48-3,70$ & $<0,001$ \\
\hline Contato com gatos & 0,451 & 0,161 & 7,891 & 1,57 & $1,14-2,15$ & 0,005 \\
\hline \multicolumn{7}{|l|}{ Neosporose $^{c}$} \\
\hline Criação com acesso à rua & 0,966 & 0,238 & 16,492 & 2,62 & $1,64-4,18$ & $<0,001$ \\
\hline
\end{tabular}

próximas foram encontradas por Gonçalez et al. (2010) em cães de abrigo em Avaré/SP, Coiro et al. (2011) em Botucatu/SP e Fernandes et al. (2013) em Natal/RN com 9,3\% (28/300), $7,6 \%(23 / 302)$ e $6,8 \%(25 / 365)$.

Fernandes et al. (2013) corroboram a afirmação de que diferenças na percentagem de positividade podem ser explicadas pela variedade de fatores que influenciam a ocorrência da leptospirose, com destaque para a topografia, região, temperatura, umidade, precipitações pluviométricas, reservatórios selvagens, reservatórios domésticos e outros fatores ambientais, bem como pela diferença nas populações caninas estudadas. Portanto, em virtude de todas essas variáveis, é possível compreender que a soropositividade da doença apresenta flutuações temporais e regionais (Genovez 2016). De uma forma geral, os municípios analisados no presente trabalho mantiveram taxas de positividade relativamente semelhantes, apesar de estarem localizados em mesorregiões diferentes.
Os sorovares com predominância de reações sorológicas são pertencentes ao sorogrupo Icterohaemorrhagiae (sorovares Icterohaemorrhagiae e Copenhageni) e apresentam como principais hospedeiros de manutenção os roedores sinantrópicos. Desses animais, o Rattus novergicus (ratazana de esgoto) ocupa posição de destaque, embora o Rattus rattus (rato-do-telhado) e o Mus musculus (camundongo) também possam eliminar leptospiras patogênicas. Esses roedores são resistentes à doença clínica e atuam como portadores sadios pois albergam o agente nos túbulos renais e eliminam a bactéria no meio ambiente pela urina, contaminando a água e os alimentos oferecidos aos cães, além de utensílios usados no manejo dos animais como bebedouros e comedouros (Paes 2016). Silva et al. (2009), Lemos et al. (2010) e Morikawa et al. (2015) também encontraram o sorovar Icterohaemorrhagiae como um dos mais prevalentes. Já o sorovar Copenhagheni ficou entre os mais reagentes nos estudos de Tesserolli et al. (2005), Gonçalez et al. (2010) e Silva et al. (2016). 
Reações positivas para o sorovar Bratislava tiveram frequência de 11,3\%. Paes (2016) afirma que embora os cães sejam os hospedeiros de manutenção do sorovar Canicola, esses animais também têm sido considerados hospedeiros incidentais de outros sorovares, dentre eles o Bratislava, sendo também relatado como causa de doença nessa espécie e considerado emergente ou reemergente em outros países. Batista et al. (2005) em cães da campanha de vacinação anti-rábica do município de Campina Grande/PB e Gonçalez et al. (2010) em cães de abrigo no município de Avaré/SP também obtiveram este sorovar como o mais prevalente. Dreer et al. (2013), em cães de abrigos em Umuarama/PR, encontraram este sorovar em $37,5 \%$ das amostras e atribuíram a um estreito contato com os cavalos infectados que também encontravamse neste abrigo, usados como animais de tração na área urbana daquela cidade. Em inquéritos sorológicos realizados em equinos, no Brasil, Icterohaemorrhagiae é o sorovar predominante, estando mais relacionado com casos clínicos graves. No entanto, também têm sido encontrados plantéis de equinos com predomínio de reações sorológicas para os sorovares Pomona, Grippotyphosa e Bratislava (Genovez 2016). Vale salientar que é comum, em vários municípios do Estado da Paraíba, a ocorrência de equinos circulando livremente no ambiente urbano.

O sorovar Canicola é reconhecidamente o mais encontrado em cães e foi apontado como o quarto mais prevalente neste estudo. Esta espécie é a principal hospedeira desse sorovar, que apresenta adaptação ao tecido renal canino, podendo ser eliminado pelo portador por longo tempo constituindo importante fonte de infecção para o homem. Vários autores também encontraram este sorovar como um dos mais prevalentes (Coiro et al. 2011, Dreer et al. 2013, Fontes et al. 2013, Morikawa et al. 2015, Silva et al. 2016, Mascolli et al. 2016), no entanto, o que se vem observando ao longo do tempo é a crescente ocorrência de outros sorovares de Leptospira spp. causando doença clínica nos cães (Paes 2016).

Em relação ao sorovar Pomona, o mesmo já foi identificado em outros estudos de soropositividade da leptospirose em cães no Brasil, porém não como um dos mais prevalentes (Magalhães et al. 2006, Fontes et al. 2013). Países como EUA e Alemanha tem experimentado uma elevação na ocorrência de sorovares considerados não usuais em cães doentes como Pomona, Bratislava, Autumnalis e Grippothyphosa (Paes 2016). Os suínos e bovinos são os hospedeiros de manutenção do sorovar Pomona, reforçando a ideia de possível contato com estas espécies mantenedoras no ambiente.

A ocorrência de reações positivas para os sorovares Grippotyphosa, Australis, Castellonis e Bataviae, embora em menores porcentagens, aponta a importância da população de roedores na transmissão da doença, visto que esses animais são os hospedeiros de manutenção dessas sorovariedades, reforçando então a necessidade de programas de controle de roedores com adoção de medidas ofensivas como desratização além de medidas preventivas através da inclusão de modificações ambientais (antirratização) e educação em saúde (Ellis 2015, Fernandes et al. 2013).

De acordo com Paes (2016), os inquéritos sorológicos realizados em áreas urbanas no Brasil têm encontrado predomínio dos sorovares Icterohaemorrhagiae e Canicola, apesar de uma relativa variação ou regionalização de certos sorovares. 0 aumento da ocorrência desses "novos" sorovares pode ser justificado pelo controle da doença com o uso de vacinas contendo os sorovares clássicos (Canicola e Icterohaemorrhagiae) e pelo contato ou coabitação de cães e outras espécies domésticas ou animais silvestres. Dessa forma, reforça-se ainda mais a importância da pesquisa continuada no desenvolvimento das vacinas contra a doença e a necessidade da inclusão de novos sorovares visando a elaboração de vacinas mais efetivas. Apesar da baixa frequência de animais soropositivos no presente trabalho, nota-se que anticorpos para sorovares importantes na espécie canina foram encontrados e que poderiam ser evitados com as vacinas comercializadas atualmente. Entretanto, com os dados obtidos dos questionários epidemiológicos verificou-se pouca utilização de vacinas antileptospirose na região, uma vez que somente $20,9 \%$ dos cães estudados tinham sido vacinados pelo menos uma vez na vida.

Com relação aos fatores de risco, os resultados mostram que cães com idade acima de 48 meses tem 2,92 vezes mais chances de adquirir a infecção. Dados semelhantes também foram relatados por Greene et al. (2006) e Mascolli et al. (2016) podendo ser justificado pelo tempo de exposição ao agente, já que animais mais velhos têm mais tempo para entrar em contato com o agente etiológico. Pode-se atribuir também à chegada da maturidade sexual dos animais, na qual os cães têm o hábito de lamber e cheirar as genitálias podendo entrar em contato com vestígios de urina contaminada; além disso, filhotes normalmente são alvo de cuidados maiores por parte dos proprietários, permanecendo em ambientes mais protegidos, inclusive durante a noite, o que diminui seu contato com possíveis fontes de infecção (Greene et al. 2006).

A não definição da raça também foi apontada como fator de risco para leptospirose. Animais sem raça definida, geralmente, têm mais acesso à rua, o que aumenta o risco de exposição às leptospiras. Os cães com acesso à rua tiveram um risco 1,57 vezes maior de se infectarem em relação àqueles que não tiveram acesso à rua, uma vez que animais soltos se expõem mais ao risco de contrair a leptospirose pelo contato com outros animais doentes, áreas alagadiças ou mesmo com os principais reservatórios da espiroqueta constituídos pelos roedores sinantrópicos. Azevedo et al. (2011) e Mascolli et al. (2016) também encontraram essas categorias como fatores de risco para a infecção por Leptospira spp.

Não foi observada associação entre a variável presença de ratos e a ocorrência da infecção embora sorovares mantidos por estes animais foram apontados entre os mais frequentes. Fernandes et al. (2013) não obtiveram nenhuma associação entre as variáveis estudadas e a ocorrência da infecção apesar dos sorovares prevalentes estarem relacionados com roedores. Uma explicação para isso seria o constrangimento, por parte dos proprietários, ao responderem afirmativamente a questão sobre presença de roedores na residência, o que os leva a uma possível omissão da informação.

Para Toxoplasma gondii 22,1\% (231/1043) dos cães foram soropositivos. Ullmann et al. (2008) em estudo retrospectivo na cidade de Botucatu/SP com 1.097 amostras obtiveram 299 reagentes $(27,25 \%)$. Resultados semelhantes também foram obtidos por Moura et al. (2009) em Lages e Balneário Camboriú/SC com 22,3\% (89/400) de soroprevalência e Lopes et al. (2011) em Teresina/PI com 18\% (100/530). Já Azevedo et al. (2005) em Campina Grande/PB, Langoni et al. (2006) e Mascolli et al. (2015) no interior de São Paulo 
obtiveram prevalências maiores com 45,1\% (129/286), 33,1\% (258/780) e 55,1\% (314/570) respectivamente. A literatura mostra que taxas de soroprevalência de T. gondii podem apresentar variações consideráveis, já que a transmissão está associada à características geo-climáticas regionais e fatores epidemiológicos, como o número de felinos infectados na área estudada, manejo dos animais, hábitos e comportamentos culturais, condições sócio-econômicas e práticas sanitárias na comunidade, além dos aspectos intrínsecos do parasita como a variabilidade genética (Silva et al. 2010, Mascolli et al. 2015).

Ao considerar a idade dos animais como fator de risco para T. gondii nota-se que animais com idade $>48$ meses possuem 1,74 vezes mais chance de serem soropositivos. Fato semelhante foi também observado por Azevedo et al. (2005), Langoni et al. (2006), Lopes et al. (2011) e Dantas et al. (2014) em que as taxas relativas mais elevadas de infecção foram encontradas com o aumento da idade. A infecção pós-natal é uma das principais formas de transmissão da toxoplasmose, assumindo importância, em função da idade, para os animais adultos, visto que há risco maior de entrarem em contato com possíveis fontes de infecção e as mais variadas vias de transmissão (Dantas et al. 2014).

Alimentação dos animais à base de comida caseira ou mista (ração comercial e comida caseira) também foi considerada fatores de risco para T. gondii. De acordo com Silva \& Silva (2016) a transmissão pela via oral é a mais importante para a infecção tanto na população humana quanto animal. Vale salientar que essa comida caseira constitui muitas vezes de restos de alimentação humana podendo ser composta de carnes cruas ou mal cozidas. 0 hábito de alimentação de sobras para animais de estimação é bem estabelecido entre os donos de cães no Brasil e este tipo de comportamento favorece a propagação da infecção por T. gondii (Silva et al. 2010). Resultados semelhantes que também suportam esta associação foram relatados por Moura et al. (2009), Silva et al. (2010) e Mascolli et al. (2015). Dentre os cinco centros urbanos estudados, o município de Cajazeiras foi o que apresentou maior taxa de positividade para toxoplasmose com $60 \%$ (IC 95\%: 51,$4 ; 68,6$ ) (Quadro 1 ), o que possivelmente se refere ao fato de que dos 125 animais amostrados 78,4\% se alimentavam de comida caseira ou de forma mista. Fato semelhante ocorreu com o município de Sousa, com a segunda maior soropositividade para toxoplasmose e 73,6\% dos cães com o mesmo tipo de alimentação. Cabe ressaltar que tais municípios apresentam em boa parte do ano clima quente e seco, enquanto que João Pessoa, com clima quente e úmido, apresentou a taxa mais baixa de positividade (11,2\%); no entanto, a maioria dos cães desta localidade era alimentada com ração comercial. Dessa forma, o manejo por parte de seus tutores através do hábito alimentar possivelmente teve influência nos resultados para T. gondii.

Quando analisada a presença de outras espécies animais em contato com os cães, a análise estatística demonstra que a convivência com gatos evidenciou um risco de 1,57 mais chances, revelando a influência da coabitação entre as duas espécies na ocorrência de anticorpos contra T. gondii, fato esse plausível, uma vez que a espécie felina atua como hospedeira definitiva e agente de disseminação de T. gondii no ambiente. Azevedo et al. (2005) e Moura et al. (2009) também observaram que a coabitação com gatos representa um fator de risco para a soropositividade dos cães. Nesse contexto, ressalte-se a importância da destinação adequada das fezes dos gatos com o objetivo de evitar a contaminação ambiental de oocistos e, consequentemente, infecção de outros animais e seres humanos.

Quanto à neosporose, dos 1.043 cães 80 apresentaram anticorpos anti-Neospora caninum resultando em soropositividade de 7,7\%. Frequências similares ao presente estudo foram constatadas por Azevedo et al. (2005), 8,4\% (24/286), utilizando cães de campanha de vacinação anti-rábica em Campina Grande/PB, Jesus et al. (2006), 12,1\% (50/415), nos municípios de Salvador e Lauro de Freitas/BA com cães domiciliados e errantes, Dantas et al. (2013), 6,5\% (31/476), analisando cães provenientes de atendimento de clínicas particulares em Natal/RN, e Mascolli et al. (2015), 7,02\% (40/570), em cães domiciliados de zona urbana, periurbana e rural de Ibiúna-SP. Resultados superiores foram constatados por Moraes et al. (2008) na Microrregião da Serra de Botucatu/SP e Fridlund-Plugge et al. (2008) em Curitiba/PR, ambos os trabalhos utilizando cães de áreas urbana, periurbana e rural com 25,4\% (245/963) e 18,7\% (101/556) de soropositividade, respectivamente. Entretanto, frequências inferiores foram encontradas por Coiro et al. (2011) em Botucatu/SP analisando cães domiciliados e peridomiciliados com 1,98\% (6/302) e Lopes et al. (2011) em cães atendidos no Hospital Veterinário da Universidade Federal do Piauí com 3,2\% (17/530) de soropositividade.

A baixa soropositividade de neosporose pode ser justificada pelo fato desta enfermidade ter maior ocorrência na zona rural. Moraes et al. (2008) verificaram que cães de zona periurbana apresentam índices de soropositividade maior do que em área urbana, no entanto, Mascolli et al. (2015) não observaram diferenças significativas entre os cães urbanos, periurbanos e rurais. De acordo com Aguiar et al. (2006), essa variabilidade na soropositividade observada nos estudos anteriores pode estar relacionada a dados referentes aos animais, como procedência, manejo, soropositividade ou não a outros agentes abortivos, assim como a profilaxia aplicada para os mesmos.

0 fator de risco para $N$. caninum apontado após a regressão logística foi o tipo de criação com acesso à rua. Deve-se considerar que este tipo de manejo pode propiciar inúmeras possibilidades de infecção pelo contato com potenciais hospedeiros intermediários e possibilidades de caça ao contrário dos cães domiciliados, que raramente entram em contato com carne e vísceras contaminadas e hospedeiros que facilitam o contato com o agente (Magalhães et al. 2009). 0 município com maior índice de positividade para neosporose, Sousa, com 31,2\% (IC 95\%: 23,1; 39,3\%), refletiu essa característica com mais de $50 \%$ dos animais amostrados com algum tipo de acesso à rua. Deve-se, portanto, atentar para o manejo desses animais reforçando a importância do estudo dos fatores de risco para a compreensão do comportamento das doenças em determinada população.

Magalhães et al. (2009) observaram maior ocorrência de anticorpos contra $N$. caninum em cães errantes quando comparados aos domiciliados na cidade de Ilhéus/BA. 0 mesmo foi observado por Mineo et al. (2004) em Minas Gerais e Jesus et al. (2006) também na Bahia, entretanto, sem diferença significativa. Vale lembrar que no presente estudo, apesar de os animais terem acesso às ruas, todos possuíam proprietários, o que os difere dos cães errantes dos 
estudos anteriores. Azevedo et al. (2005) trabalhando com cães urbanos domiciliados de Campina Grande/PB também constataram que cães com acesso à rua tinham maiores chances de soropositividade do que aqueles que permaneciam exclusivamente em ambiente doméstico.

\section{CONCLUSÕES}

Conclui-se que cães de cinco centros urbanos do Estado da Paraíba estão expostos às infecções por Leptospira spp., Toxoplasmagondii e Neospora caninum, evidenciadas pela detecção de anticorpos, indicando que estes agentes circulam nesta população.

Sugere-se melhor manejo alimentar dos animais, controle no acesso a ambientes externos e destino adequado das fezes dos gatos.

\section{REFERÊNCIAS}

Aguiar D.M., Cavalcante G.T., Rodrigues A.A., Labruna M.B., Camargo L.M., Camargo E.P. \& Gennari S.M. 2006. Prevalence of anti-Neospora caninum in cattle and dogs from western Amazon, Brazil, in association with some possible risk factors. Vet. Parasitol. 142(1/2):71-77. http://dx.doi. org/10.1016/j.vetpar.2006.06.014. PMid:16857319.

Azevedo S.S., Batista C.S.A., Vasconcellos S.A., Aguiar D.M., Ragozo A.M.A., Rodrigues A.A.R., Alves C.J. \& Gennari S.M. 2005. Seroepidemiology of Toxoplasma gondii and Neospora caninum in dogs from the state of Paraiba, Northeast region of Brazil. Res. Vet. Sci. 79(1):51-56. http:// dx.doi.org/10.1016/j.rvsc.2004.10.001. PMid:15894024.

Azevedo S.S., Fernandes A.R.F., Queiroga I.M.B.N., Alves C.J., Morais Z.M., Santos C.S.A.B. \& Vasconcellos S.A. 2011. Ocorrência e fatores de risco associados à leptospirose em cães atendidos em hospital veterinário no semiárido paraibano. Braz. J. Vet. Res. Anim. Sci. 48(2):161-166. http:// dx.doi.org/10.11606/S1413-95962011000200009.

Batista C.S.A., Alves C.J., Azevedo S.S., Vasconcellos S.A., Morais Z.M., Clementino I.J., Alves F.A.L., Lima F.S. \& Araújo Neto J.O. 2005. Soroprevalência e fatores de risco para a leptospirose em cães de Campina Grande, Paraíba. Arq. Bras. Med. Vet. Zootec. 57(Supl.2):179-185. http://dx.doi.org/10.1590/ S0102-09352005000800008.

Camargo M.E. 1964. Improved technique of indirect immunofluorescence for serological diagnosis of toxoplasmosis. Revta Inst. Med. Trop. 6:117118. PMid: 14177810 .

Castro J.R., Salaberry S.R.S., Souza M.A. \& Lima-Ribeiro A.M.C. 2011. Sorovares de Leptospira spp. predominantes em exames sorológicos de caninos e humanos no município de Uberlândia, Estado de Minas Gerais. Revta Soc. Bras. Med. Trop. 44(2):217-222. http://dx.doi.org/10.1590/S003786822011005000012 .

Coiro C.J., Langoni H., Silva R.C. \& Ullmann L.S. 2011. Fatores de risco para leptospirose, leishmaniose, neosporose e toxoplasmose em cães domiciliados e peridomiciliados em Botucatu/SP. Vet. Zootec. 18(3):393-407.

Dantas S.B.A., Fernandes A.R.F., Souza Neto O.L., Mota R.A., Alves C.J. \& Azevedo S.S. 2013. Ocorrência e fatores de risco associados às infecções por Toxoplasma gondii e Neospora caninum em cães no município de Natal, Estado do Rio Grande do Norte, Nordeste do Brasil. Ciência Rural 43(11):2042-2048. http://dx.doi.org/10.1590/S0103-84782013001100020.

Dantas S.B.A., Fernandes A.R.F., Neto O.L.S., Mota R.A., Alves C.J. \& Azevedo S.S. 2014. Fatores de risco para a ocorrência de anticorpos contra Toxoplasma gondii e Neospora caninum em cães domiciliados no Nordeste do Brasil. Semina, Ciênc. Agrárias 35(2):875-882. http://dx.doi.org/10.5433/16790359.2014v35n2p875.

Dohoo I.R., Ducrot C., Fourichon C., Donald A. \& Hurnik D. 1997. An overview of techniques for dealing with large numbers of independent variables in epidemiologic studies. Prev. Vet. Med. 29(3):221-239. http://dx.doi. org/10.1016/S0167-5877(96)01074-4. PMid:9234406.

Dreer M.K.P., Gonçalves D.D., Caetano I.C.S., Gerônimo E., Menegas P.H., Bergo D., Lopes-Mori F.M.R., Benitez A., Freitas J.C., Evers F., Navarro I.T. \& Martins L.A. 2013. Toxoplasmosis, leptospirosis and brucellosis in stray dogs housed at the shelter in Umuarama municipality, Paraná, Brazil. J. Venom. Anim. Toxins incl. Trop. Dis. 19(1):1-5. http://dx.doi.org/10.1186/1678-919919-1. PMid:23849430.

Dubey J.P., Carpenter J.L., Speer C.A., Topper M.J. \& Uggla A. 1988. Newly recognized fatal protozoan disease of dogs. J. Am. Vet. Med. Assoc. 192(9):1269-1285. PMid:3391851.

Dubey J.P., Huong L.T.T., Sundar N. \& Su C. 2007. Genetic characterization of Toxoplasma gondii isolates in dogs from Vietnam suggests their South American origin. Vet. Parasitol. 146(3/4):347-351. http://dx.doi. org/10.1016/j.vetpar.2007.03.008. PMid:17442492.

Dubey J.P., Jenkins M.C., Rajendran C., Miska K., Ferreira L.R., Martins J., Kwok O.C.H. \& Choudhary S. 2011. Gray wolf (Canis Lupus) is a natural definitive host for Neospora caninum. Vet. Parasitol. 181(2/4):382-387. http://dx.doi. org/10.1016/j.vetpar.2011.05.018. PMid:21640485.

Dubey J.P., Lago E.G., Gennari S.M., Su C. \& Jones J.L. 2012. Toxoplasmosis in humans and animals in Brazil: high prevalence, high burden of disease, and epidemiology. Parasitol. 139(11):1375-1424. http://dx.doi.org/10.1017/ S0031182012000765. PMid:22776427.

Ellis W.A. 2015. Animal leptospirosis, p.99-137. In: Adler B. (Ed), Leptospira and Leptospirosis. Springer-Verlag, Heidelberg, Berlin.

Fernandes A.R.F., Fernandes A.G., Araújo V.J.A., Higino S.S.S., Silva M.L.C.R., Alves C.J. \& Azevedo S.S. 2013. Soroepidemiologia da leptospirose canina na região metropolitana de Natal, estado do Rio Grande do Norte. Braz. J. Vet. Res. Anim. Sci. 50(3):226-232. http://dx.doi.org/10.11606/issn.16784456.v50i3p226-232.

Fontes A.M.M., Rufino C.A., Assunção T.M., Silva J.E.S., Belarmino D.A., Santos D.G., Lopes P.D. \& Barbudo Filho J. 2013. Soroprevalência de leptospirose em cães no município de Andradina/SP. Ciênc. Agrár. Saúde 9:21-25.

Fridlund-Plugge N., Montiani-Ferreira F., Richartz R.R.T.B., Pizzol J.D., Machado Junior P.C., Patrício L.F.L., Rosinelli A.S. \& Locatelli-Dittrich R. 2008. Frequency of antibodies against Neospora caninum in stray and domiciled dogs from urban, periurban and rural areas from Paraná state, southern Brazil. Revta Bras. Parasitol. Vet. 17(4):222-226. http://dx.doi. org/10.1590/S1984-29612008000400010. PMid:19265582.

Genovez M.E. 2016. Leptospirose em animais de produção, p.378-386. In Megid J., Ribeiro M.G. \& Paes A.C. (Eds), Doenças Infecciosas em Animais de Produção e de Companhia. Roca, São Paulo.

Gonçalez C.C., Paes A.C., Langoni H., Da Silva R.C., Greca H., Camossi L.G., Guimarães F.F. \& Ullmann L.S. 2010. Anticorpos para Leptospira spp., Toxoplasma gondii e Neospora caninum em cães errantes albergados em canil privado. Arq. Bras. Med. Vet. Zootec. 62(4):1011-1014. http://dx.doi. org/10.1590/S0102-09352010000400037.

Gondim L.F.P., McAllister M.M., Pitt W.C. \& Zemlicka D.E. 2004. Coyotes (Canis latrans) are definitive hosts of Neospora caninum. Int. J. Parasitol. 34(2):159161. http://dx.doi.org/10.1016/j.ijpara.2004.01.001. PMid:15037103.

Greene C.E., Sykes J.E., Brown C.A. \& Hartman K. 2006. Leptospirosis, p.402417. In: Greene C.E. (Ed.), Infectious Diseases of the Dog and Cat. 3rd ed. Elsevier, St Louis.

Hosmer D.W. \& Lemeshow S. 2000. Interpretation of the fitted logistic regression model, p.49-82. In: Hosmer D.W. \& Lemeshow S. (Eds), Applied Logistic Regression. John Wiley \& Sons, New York. http://dx.doi. org/10.1002/0471722146.

Jesus E.E.V., Santos P.O.M., Barbosa M.V.F., Pinheiro A.M., Gondim L.F.P., Guimarães J.E. \& Almeida M.A.O. 2006. Frequência de anticorpos antiNeospora caninum em cães nos municípios de Salvador e Lauro de Freitas, 
Estado da Bahia, Brasil. Braz. J. Vet. Res. Anim. Sci. 43(1):5-10. http:// dx.doi.org/10.11606/issn.1678-4456.bjvras.2006.26511.

King J.S., Slapeta J., Jenkins D.J., Al-Qassab S.E., Ellis J.T. \& Windsor P.A. 2010. Australian dingoes are definitive hosts of Neospora caninum. Int. J. Parasitol. 40(8):945-950. http://dx.doi.org/10.1016/j.ijpara.2010.01.008. PMid:20149793.

Langoni H., Modolo J.R., Pezerico S.B., Silva R.C., Castro A.P.B., Silva A.V. \& Padovani C.R. 2006. Serological profile of anti-Toxoplasma gondii antibodies in apparently healthy dogs of the city of Botucatu, São Paulo state, Brazil. J. Venom. Anim. Toxins incl. Trop. Dis. 12(1):142-148. http://dx.doi. org/10.1590/S1678-91992006000100012.

Lemos J.P., Melo C.B. \& Viegas S.A.R.A. 2010. Análise sorológica de Leptospira spp. em cães errantes no município de Aracaju. Revta Cient. Eletrônica Med. Vet. 14(1):1-16.

Lobato J., Silva D.A.O., Mineo T.W.P., Amaral J.D.H.F., Segundo G.R.S., Costa-Cruz J.M., Ferreira M.S., Borges A.S. \& Mineo J.R. 2006. Detection of immunoglobulin G antibodies to Neospora caninum in humans: high Seropositivity rates in patients who are infected by human immunodefi ciency virus or have neurological disorders. Clin. Vaccine Immunol. 13(1):84-89. http://dx.doi. org/10.1128/CVI.13.1.84-89.2006. PMid:16426004.

Lopes M.G., Mendonça I.L., Fortes K.P., Amaku M., Pena H.F.J. \& Gennari S.M. 2011. Presence of antibodies against Toxoplasma gondii, Neospora caninum and Leishmania infantum in dogs from Piauí. Revta Bras. Parasitol. Vet. 20(2):111-114. http://dx.doi.org/10.1590/S1984-29612011000200004. PMid:21722484.

Magalhães D.F., Silva J.A., Moreira E.C., Wilke V.M.L., Haddad J.P.A. \& Meneses J.N.C. 2006. Prevalência de aglutininas anti-Leptospira interrogans em cães de Belo Horizonte, Minas Gerais, 2001 a 2002. Arq. Bras. Med. Vet. Zootec. 58(2):167-174. http://dx.doi.org/10.1590/S0102-09352006000200004.

Magalhães V.C.S., Sicupira P.M.L., Gondim L.F.P. \& Munhoz A.D. 2009. Frequência de anticorpos contra Neospora caninum em cães do município de Ilhéus, Bahia. Ciênc. Anim. Bras. 10(1):306-311.

Mascolli R., Soto F.R.M., Bernardi F., Ito F.H., Pinheiro S.R., Guilloux A.G.A., Azevedo S.S., Silva P.V., Gennari S.M., Fernandes A.R.F., Pena H.F.J. \& Vasconcellos S.A. 2015. Seroprevalence and risk factors for toxoplasmosis and neosporosis in the dog population of Ibiúna, São Paulo, Brazil. Semina, Ciênc. Agrárias 36(6):3777-3786.

Mascolli R., Soto F.R.M., Bernardi F., Ito F.H., Pinheiro S.R., Guilloux A.G.A., Azevedo S.S., Fernandes A.R.F., Keid L.B., Morais Z.M., Souza G.O. \& Vasconcellos S.A. 2016. Prevalência e fatores de risco para a leptospirose e brucelose na população canina da Estância Turística de Ibiúna, São Paulo, Brasil. Arqs Inst. Biológico, São Paulo, 83:1-7.

McAllister M.M., Dubey J.P., Lindsay D.S., Jolley W.R., Wills R.A. \& McGuire A.M. 1998. Dogs are definitive hosts of Neospora caninum. Int. J. Parasitol. 28(9):1473-1478. http://dx.doi.org/10.1016/S0020-7519(98)00138-6. PMid:9770635.

Mineo T.W.P., Silva D.A.O., Näslund K., Björkman C., Uggla A. \& Mineo J.R. 2004. Toxoplasma gondii and Neospora caninum serological status of different canine populations from Uberlândia, Minas Gerais. Arq. Bras. Med. Vet. Zootec. 56(3):414-417. http://dx.doi.org/10.1590/S010209352004000300022 .

Moraes C.C.G., Megid J., Pituco E.M., Okuda L.H., Del Fava C., Stefano E. \& Crocci A.J. 2008. Ocorrência de anticorpos anti-Neospora caninum em cães da microrregião da Serra de Botucatu, Estado de São Paulo, Brasil. Revta Bras. Parasitol. Vet. 17(1):1-6. http://dx.doi.org/10.1590/S198429612008000100001.
Morikawa V.M., Bier D., Pellizzaro M., Ullmann L.S., Paploski I.A.D., Kikuti M., Langoni H., Biondo A.W. \& Molento M.B. 2015. Seroprevalence and seroincidence of Leptospira infection in dogs during a one-year period in an endemic urban area in Southern Brazil. Revta Soc. Bras. Med. Trop. 48(1):5055. http://dx.doi.org/10.1590/0037-8682-0213-2014. PMid:25860464.

Moura A.B., Souza A.P., Sartor A.A., Bellato V., Teixeira E.B., Pisetta G.M. \& Heusser Junior A. 2009. Ocorrência de anticorpos e fatores de risco para infecção por Toxoplasma gondii em cães, nas cidades de Lages e Balneário Camboriú, Santa Catarina, Brasil. Revta Bras. Parasitol. Vet. 18(3):52-56. http://dx.doi.org/10.4322/rbpv.01803009. PMid:19772776.

OIE 2014. Reference Laboratory Reports Activities. World Organisation for Animal Health, Paris. Disponível em <http://www.oie.int/fileadmin/ Home/fr/Our_scientific_expertise/reflabreports/2014/report_204_2014_ Leptospirosis_UNITED_KINGDOM.pdf> Acesso em 1 ago. 2016.

Paes A.C. 2016. Leptospirose canina, p.356-377. In: Megid J., Ribeiro M.G. \& Paes A.C. (Eds), Doenças Infecciosas em Animais de Produção e de Companhia. Roca, São Paulo.

Reichel M.P., Ayanegui-Alcérreca M.A., Gondim L.F.P. \& Ellis J.T. 2013. What is the global economic impacto of Neospora caninum in cattle: the billion dollar question. Int. J. Parasitol. 43(2):133-142. http://dx.doi.org/10.1016/j. ijpara.2012.10.022. PMid:23246675.

Reichmann M.L.A.B., Pinto H.B.F. \& Nunes V.P. 1999. Vacinação Contra Raiva de Cães e Gatos. Secretaria de Estado da Saúde, São Paulo. Disponível em <http://www.saude.sp.gov.br/resources/instituto-pasteur/pdf/manuais/ manual_03.pdf> Acesso em 10 out. 2015.

Silva R.C., Souza L.C., Langoni H., Tanaka E.M., Lima V.Y. \& Silva A.V. 2010. Risk factors and presence of antibodies to Toxoplasma gondii in dogs from the coast of São Paulo State, Brazil. Pesq. Vet. Bras. 30(2):161-166. http:// dx.doi.org/10.1590/S0100-736X2010000200011.

Silva R.C. \& Silva A.V. 2016. Toxoplasmose em animais domésticos, p.10401053. In: Megid J., Ribeiro M.G. \& Paes A.C. (Eds), Doenças Infecciosas em Animais de Produção e de Companhia. Roca, São Paulo.

Silva R.C., Lima V.Y., Silva A.V., Souza L.C. \& Langoni H. 2016. Seroepidemiological survey for canine leptospirosis in the coast of São Paulo state, Brazil. Vet. Zootec. 23(3):495-503.

Silva W.B., Simões L.B., Padovani C.R., Langoni H., Lopes A.L.S. \& Modolo J.R. 2009. Inquérito sorológico e distribuição espacial da leptospirose canina em área territorial urbana da cidade de Botucatu, São Paulo. Vet. Zootec. 16(4):656-668.

Tesserolli G.L., Alberti J.V.A., Agottani J.V.B., Fayzano L. \& Warth J.F.G. 2005. Soroprevalência para leptospirose em cães de Curitiba, Paraná. Revta Acad. Ciênc. Anim. 3(4):35-38.

Thrusfield M. 2007. Data collection and management, p.188-213. In: Ibid. (Ed.), Veterinary Epidemiology. 3rd ed. Wiley-Blackwell, Oxford.

Ullmann L.S., Guimarães F.F., Fornazari F., Tomé R.O., Camossi L.G., Greca H., Silva R.C., Menozzi B.D. \& Langoni H. 2008. Ações de vigilância continuada, papel do cão como sentinela para toxoplasmose. Revta Bras. Parasitol. Vet. 17(1):345-347.

WHO 1990. Techniques applied to the study of dog populations, p.15-37. In: Ibid. (Ed.), Guidelines for Dog Population Management. World Health Organization, Geneva.

Zar J.H. 1999. Multiple comparasion, p.520-531. In: Ibid. (Ed.), Biostatistical Analysis. 4th ed. Prentice Hall, Upper Saddle River, New Jersey. 